\title{
Study on Design and Evaluation of Multiple Main Supply Model
}

\section{Evaluation System of Agricultural Information Service}

\author{
Qiong $\mathrm{Wu}^{1}$ \\ ${ }^{1}$ Wuhan Donghu University, Wuhan, Hubei, 430212 \\ 346591653@163.com
}

\begin{abstract}
KEYWORDS: Agriculture Information System; Multiple Main Supply Model
\end{abstract}
\begin{abstract}
China's agricultural information construction started late, the overall level compared with developed countries there is a big gap. In order to improve the level of agricultural information, we must deepen the theoretical research of agricultural information, pay attention to the many problems that exist in practice and promptly resolved. Comprehensive domestic and foreign experts and scholars in the paper establishes the index system of agricultural information and evaluation research, he pointed out that the conduct of basic principles to build the county agricultural information and evaluation index system was constructed county (district) level Agricultural Information Evaluation system, information technology index as the theoretical basis, elaborated agricultural information sub-indices, the calculation and evaluation methods of the total index.
\end{abstract}

\section{Introduction}

In general, the information can be understood as information industry, information economy, information society three basic levels, information technology refers to popularize and start to play an increasingly important role. This is expressed by the industry to improve labor productivity, reduce production costs, or the performance of the national economy to intensive economic growth mode from extensive economic growth mode, or the performance of information infrastructure and information networks to promote the social system and management It changes.

Understanding the meaning of agricultural information is still in the process of evolving, in theory there is no on the "agricultural information" concept to make an authoritative interpretation. But most scholars believe that agricultural information is the whole process of agricultural information, that is a comprehensive development and application of modern information technology in agriculture, making it penetrate into various specific aspects of agricultural production, marketing, consumption and rural social, economic and technological accelerate the transformation of traditional agriculture, greatly improve the efficiency of agricultural production and the level of agricultural productivity, promote agricultural sustainable, stable and efficient development process. Specifically it should include the following six areas: (1) agricultural resources and environment information; (2) agricultural production and agricultural management information; (3) of agricultural production and the agricultural market information; (4) agricultural science and technology education information; (5) Agricultural policies and regulations of information; (6) the rural social and economic information.

\section{The Basic Principle to Establish Agriculture Information}


Agricultural information construction is a systematic project, including the construction of infrastructure, information platform, information resources, institutional personnel, information services and external environment subsystems. Therefore, we must use the system point of view, from a system point of view, in the interconnected system, mutual restraint in describing its features, characteristics and grasp the connotation of agricultural information construction as a whole, from the construction of agricultural information service in agriculture and rural economy the purpose of starting the growth of agricultural information construction overall description and evaluation. Agricultural informatization index evaluation system as an organic whole to be able to accurately reflect and measure are the main features of the evaluation system and the status of the various elements of a more comprehensive contain. Of course, agricultural informatization index evaluation system can not be all-inclusive, but the main factor indispensable, should reflect the content of the systematic and integrity.

Scientific evaluation system must reflect the level of agricultural information, must have a theory, you can not select moot index, otherwise it will affect the overall assessment and evaluation of effectiveness. Indicators, data should be concise, easy to understand, easy to search and easy calculation, while standardized to the extent possible. Key selection reflects the key indicators of agricultural information construction, Ningquewulan with less indicators truly reflect the basic situation of agricultural information construction. Meanwhile, the index should be comparable, neither by leaving too many indicators calculation is too complex, and not because of leaving too few indicators index is too simple and can not fully reflect the overall situation of agricultural information construction.

Evaluation system must be designed to be operable, to fully consider the feasibility of data collection and measurement of its target value. Index is the unity of quality and quantity, both use specific quality, the precise amounts to reflect, so that can be referred to as indicators. Indicators simple and practical as possible, facilitate the collection and use of computers for processing. In the design of agricultural information evaluation system, there are many aspects from the theoretical analysis is important, not missing, but there is no way to quantify, quantify or high operating costs, time-consuming, is not feasible, and therefore will not be able design specifications, such as information service awareness, philosophy and other agricultural information collection release. Note that with a good subjective and objective indicators index ratio between the reduction of subjective indicators and the design of new indicators. If new indicators and subjective indicators more difficult corresponding indicators survey data collection work will increase throughout the evaluation index system maneuverability will diminish. To choose the NBS and academia recognized as common indicators, with reference to various statistical yearbooks and statistics to the development and utilization of existing data and information, not only allows users to easily understood and accepted, and easy to collect data and quantization to reduce the data collection, collation of difficulty, but also reduce the workload.

\section{Evaluation System}

Agricultural information infrastructure mainly refers to support agriculture and agricultural information resources development and utilization of various types of information technology resources. More simply, it is the "triple play", namely: computer networks, television networks and telephone networks, as well as "triple play" relevant software and hardware facilities, such as servers, PC machines, printers, televisions, telephones and so on. Agricultural information infrastructure is a necessary precondition for the construction of agricultural information and application, is an important way of agricultural information villages and households, is the 
information delivery platform for sustainable development, the level of the building directly reflects the level of development of agricultural information technology. Down through the establishment, convenient rural science and technology and economic information service network, "three rural" to provide quality and efficient information services, and vigorously promotes the process of agricultural information, to promote sustained and rapid development of agriculture and rural economy. Information network into the village, cable TV and telephone into the village is an important way to solve the last kilometers of rural informatization problem. Indicators were selected from the following aspects: (1) rural PC penetration; (2) rural telephone penetration rate; (2) cable into the village rate.

Agriculture is the substance of the information resources of agricultural information infrastructure to carry, it is also the core of the development and use of information technology, agricultural information technology a significant sign of success. Ownership of information resources determines the level of service information service system, agricultural policy, agricultural affairs, agricultural supply and demand, prices of agricultural products and agricultural technical guidance, and so to meet the diverse information needs of different users; extensive access to information and publishing route is Basic Agricultural information service lifeline for survival and development. How reasonable planning, construction and use of agricultural information resources to be effective and efficient agricultural information resources, to provide effective information support for rural economic development, but also the current agricultural information construction of key issues need to be resolved. This paper has a number of agriculture-related sites, agriculture database capacity evaluated from three aspects of Agricultural Economics class radio and television broadcast rate, people.

Agricultural Information Construction purpose is to modern information technology is widely applied to the field of agriculture to promote the sustained, stable and efficient development of agriculture, agricultural information technology can be said is the core and the pilot development of agricultural information, agricultural information technology status quo the assessment is the evaluation of agricultural information construction important content. Currently, most of the new level of application of modern information technology, agriculture is extremely low, its evaluation great difficulty, for which the index selection will study focused on the current and future period of time for rural areas to promote the application of technology, including in rural areas the proportion of Internet users, SMS users to share, receive agricultural experts and technicians from the proportion of personnel services three indicators. Effect of Agricultural Information Construction of external environmental factors very much, according to the current status of Shaanxi Agricultural Information Construction, select agricultural investment in information technology, labor education of rural households, rural telecommunications investment three indicators evaluated.

\section{Agricultural Information Evaluation Method}

Principal component analysis, also known as principal component analysis, designed to take advantage of the ideological dimension reduction, the index into a few more comprehensive index. In empirical research issues in order to comprehensively and systematically analyze problems, we must consider many factors. These factors relate generally referred to as indicators in multivariate statistical analysis, also known as variable. Since each variable in a different extent reflects certain information research questions and indicators among some correlation to each other, thus resulting statistics reflect the information to some extent overlap. In examining the issue with multivariate statistical methods, variables, too much will increase the amount of calculation and increase the complexity of analysis of the problem, it is desirable in the process of performing quantitative 
analysis, the variables involved less, get more information. Principal component analysis is to adapt to this requirement generated. Principal component analysis is a method of mathematical transformation, which the given set of relevant variables turn into another set of uncorrelated variables linear transformation, these new variables are arranged in descending order of variance. Hold variable in the mathematical transformation of the total variance constant, the first variable has the largest variance, it called the first principal component, the second largest variance of the second variable, and the first variable and uncorrelated, called the second principal component . And so on, I have a variable I principal components.

Analytic Hierarchy Process (Analytic Hierarchy Process, called AHP) is an American Operations Research Professor TL Saaty in the early 1970s made simple, flexible and practical multi-criteria decision making methods, is some of the more complex, more ambiguous question make simple method of decision-making, it is difficult for those who complete quantitative analysis of the problem. Characteristics of the Analytic Hierarchy Process is carried out on the basis of the complex nature of the decision problem, affecting factors and their internal relations in-depth analysis on the use of quantitative information makes fewer mathematical thinking, decision-making process, so as to multi-objective, multi-criteria or non-structural properties of complex decision problems provides an easy approach to decision making.

Overall rating analysis is based on expert evaluation of the above, to determine the weight of agricultural information of each index and score, score based on scores calculated for each sub-index by Delphi method, so that the index value of different types of change into standardized scores can be calculated sequentially obtain each secondary indicators index values and level indicators index value, and then calculated the total index value to reflect the degree of information construction and agricultural applications.

A method of analysis and forecast further development of the RAND Corporation and Golden formed. Delphi The name originated in ancient Greek mythology the sun god Apollo, the legendary Apollo has the ability to foresee the future. Therefore, this prediction method is named Delphi method. In 1946, the Rand Corporation for the first time with the Delphi method to analyze and predict, then the method is rapid and broad adoption.

\section{Conclusion}

Efficient high-quality information services organization system, the government must be the dominant, the construction organization, the team, information networks, information databases and agriculture organization and management system. In the agricultural business information services building, the focus should strengthen the construction of agricultural business information services market. We should establish smooth channels of information collection and dissemination of market mechanisms, timely use of agricultural business information network transmission, providing timely and accurate market information and guidance to farmers and agriculture-related enterprises, agricultural industrialization management services.

\section{Acknowledgements}

Proj: The Initial Results of 2014 Wuhan Donghu University Youth Social Science Fund Project "Agricultural Information Service Study of Multiple Subjects Supplied Perspective".

\section{REFERENCE:}


[1] Frank Ellis. Agricultural Policy in Developing Countries. Published by Press Syndicate of The University of Cambridge, 2001.

[2] R. Drury and L. Tweeten. The Costs and Benefits of Formational Agriculture [J]. Simon and Schuster, Vol9, 2001.

[3] Wang Yadong. Research on the Construction of Agricultural Informatization in China. Journal of the China Society for Scientific and Technical Information, Vol 21, No2, 2002:214-218. 